\title{
Analysis of the Relationship between Logistics Performance and Carbon Emissions in ASEAN
}

\author{
Wahyuningsih Santosa ${ }^{1}$, Yuana Jatu Nilawati ${ }^{2}$, Rifqi Pandu Kusuma ${ }^{3}$ \\ \{wahyuningsih@trisakti.ac.id ${ }^{1}$, yuana.nilawati@gmail.com², rpandukusuma@gmail.com ${ }^{3}$ \} \\ Faculty of Economics and Business, Universitas Trisakti ${ }^{1,2,3}$
}

\begin{abstract}
This study is aimed to investigate the relationship between logistics performance and environmental performance as measured by carbon emissions in ASEAN countries. The study was conducted in 10 ASEAN countries using panel data analysis from 2007 - 2018. Logistic performance is measured by the logistic performance index (LPI) and carbon emissions are measured by $\mathrm{CO} 2$ (carbon dioxide) emissions per capita. Data published by The World Bank Database. The results show that LPI and carbon emissions has a negative and significant correlation. This means that the higher the performance of logistics, the lower emissions of carbon. The results of the analysis of the relationship between the six LPI indicators on carbon emissions, show that only infrastructure and international shipments are related to carbon emissions, but in different directions. Meanwhile, customs, logistics competence, tracking and tracing and timeliness are not related to carbon emissions.
\end{abstract}

Keywords: Logistics Performance; Carbon Emissions; Trade; Urban Population

\section{Introduction}

Logistics is an inseparable part of supply chain management, where its important role in business is getting wide attention. Even Arvis stated that an effective logistics sector is now internationally recognized as one of the main drivers of development [1]. In the World Bank Report on the LPI in 2014 it was re-emphasized the significant of efficient logistics, which is now accepted by policy makers around the world widely [2]. They place logistics performance at the base of the competitiveness and economic growth program. A similar statement from, states that logistics activities will accelerate economic growth and productivity [3]. Likewise, states that an efficient logistics system is a key factor for sustainable economic growth [4].

The increase in production activities that are integrated with each other globally, the shortening of product life cycles and the intensity of global competition, have also made logistics a source of strategic competitive advantage for companies at the micro level and countries at the macro level [2]. Mustra also agrees, namely that well-functioning logistics is the most significant element of national advantages and competitiveness [5]. Increased competitiveness in turn will encourage economic growth. Another study conducted by, stated that logistics represents one of important sectors for the economic development, where the performance of logistics affects growth and development at first hand [6]. There are a number 
of other studies that state a straight relationship between logistics performance and economic development, including [7].

However, in the era of sustainability, development will not be appreciated if it only focuses on economic aspects, but must include three aspects of sustainability, namely economic, social and environmental aspects [8]. Social and environmental aspects have now become the agenda of the world community, and responsible and sustainable supply chain management (SCM) is one of issues to be focused on in this regard [9]. Furthermore, the World Bank (WB) defines a sustainable supply chain as "the management of economic, social and environmental impacts, and the encouragement of good governance practices throughout the life cycle of goods and services". World Bank also states that objective of sustainable SCM is to create, protect and improve long-term economic, social and environmental value for all stakeholders participated in producing products or services.

Karaduman stated that logistics, as an important sector in supply chain management, is increasingly receiving attention due to its role in global business and also the social and environmental impacts it can have [8]. The logistics industry consumes large amounts of energy resources, resulting in high amounts of carbon emissions [10]. In this regard, the logistics industry is faced with tremendous pressure to implement carbon management in order to increase the logistics activities efficiency for the economic development and to reduce the impact on the environment.

The important role of the logistics sector in promoting sustainable development is the main reason for conducting this study. Here we will investigate the logistical impact on the environmental aspect in this case is carbon emissions. This is also in line with government policies that pay great attention to improving national logistics performance and efforts towards sustainable development. The study was conducted on ASEAN member countries that have implemented regional markets, namely the ASEAN Economic Community (AEC) where the movement of goods and services across ASEAN countries is increasing. Studies on this topic are rarely carried out for ASEAN countries as a whole.

\section{Literature Review}

\subsection{Logistics Management}

Logistics was originally known in the world of war related to the handling of various supplies needed in war. Over time, the term logistics was adopted in business because the issue of inventory management has also become an important concern in business.

According to, logistics is an effective and efficient planning, implementing and controlling process for the flow and storage of raw materials, work-in-process inventory, finished products and other related information from point of origin to point of consumption according to customer needs [11]. Rushton et al., stated that logistics is the management of the flow between marketing and production, where there are activities between the point and time of production (supply) and the point and time of product purchase (demand) [12]. Logistics can be described as having the right type of product or service, in the right place, at the right time and in the right conditions [3]. Meanwhile, Bizoi and Sipos state that logistics is a discipline (field) that focuses on the management and coordination of supply chain activities, namely the launch of supply orders, material handling, inventory management and transportation [4]. Now, the role of logistics has been recognized as very important as part of the business system 
and is a major global economic activity. This is also supported by data showing that logistics costs are estimated at $9-20 \%$ of GDP [3].

A more comprehensive definition is provided by Sunil and Peter; Simchi-Levi; and Chang et al., where they show the number of parties involved in supply chain, as well as the functions or activities in it [13]-[15]. This provides a solid basis for the need for effective coordination and integration to achieve maximum supply chain performance. Strong management is needed so that the supply chain can run efficiently and effectively

\subsection{Logistics Performance}

In line with the increasing recognition of the important role of logistics for a country's economy, the World Bank has initiated the measurement of a country's logistics performance since 2007 by issuing the Logistics Performance Index (LPI) [16]. The WB defines LPI as the perception of a country's logistics efficiency in terms of customs operations, trade and transportation infrastructure, shipping, logistics services, traceability of goods and on time delivery. Logistics performance measurement is carried out with a value of $1-5$, where a value of 5 indicates the highest performance. The following figure shows LPI data for ASEAN countries for the period 2007 - 2018 sourced from the World Bank Database:

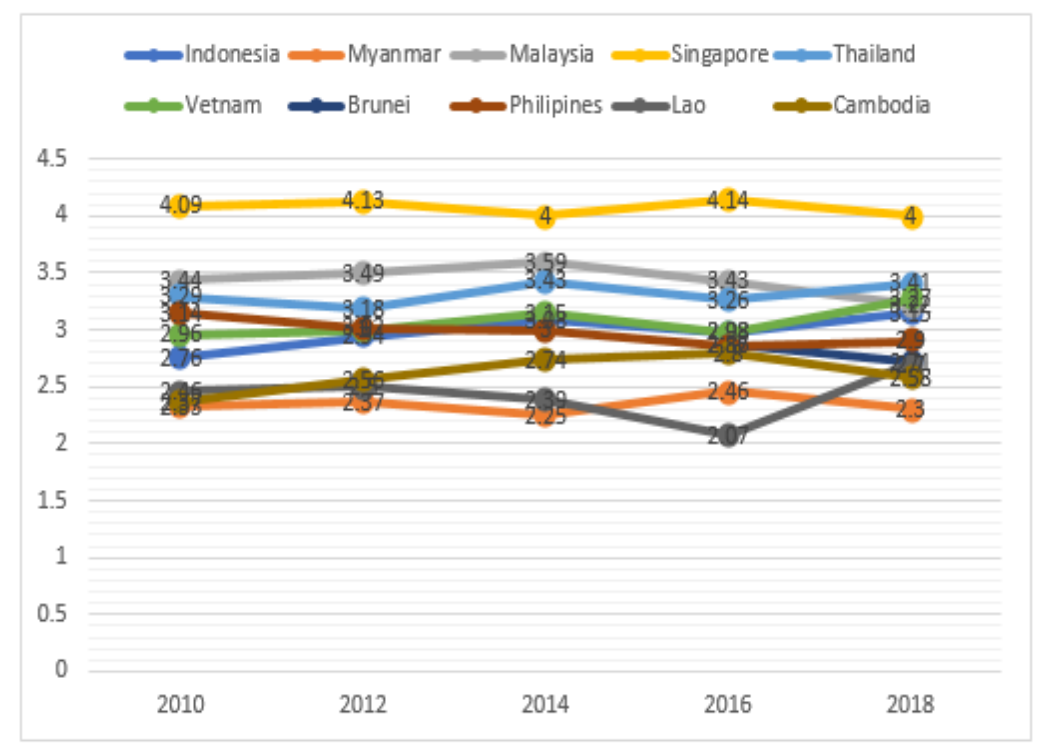

Fig. 1. LPI for ASEAN Countries: Year 2007 - 2018

From Figure 1 it can be seen that the highest LPI in ASEAN is Singapore since 2007 until now, followed by Malaysia, Thailand, Vietnam and Indonesia as the 5 countries with the highest LPI ranking in ASEAN. Malaysia always ranks second, but in 2018 it experienced a significant decline of LPI. 


\subsection{Carbon Emissions}

Carbon emissions in this research is $\mathrm{CO} 2$ emissions percapita (metric tons percapita). The measurement of carbon emissions percapita is the total amount of carbon dioxide that emitted by country as a consequence of all relevant human (production and consumption) activities, divided by the population of the country (https://unstats.un.org). Definition from World Bank stated that carbon dioxide emissions are those stemming from the burning of fossil fuels and the manufacture of cement. They include carbon dioxide produced during consumption of solid, liquid, and gas fuels and gas flaring (https://databank.worldbank.org). The following figure shows carbon emission data for ASEAN countries for the period 2007 - 2018 sourced from the World Bank Database:

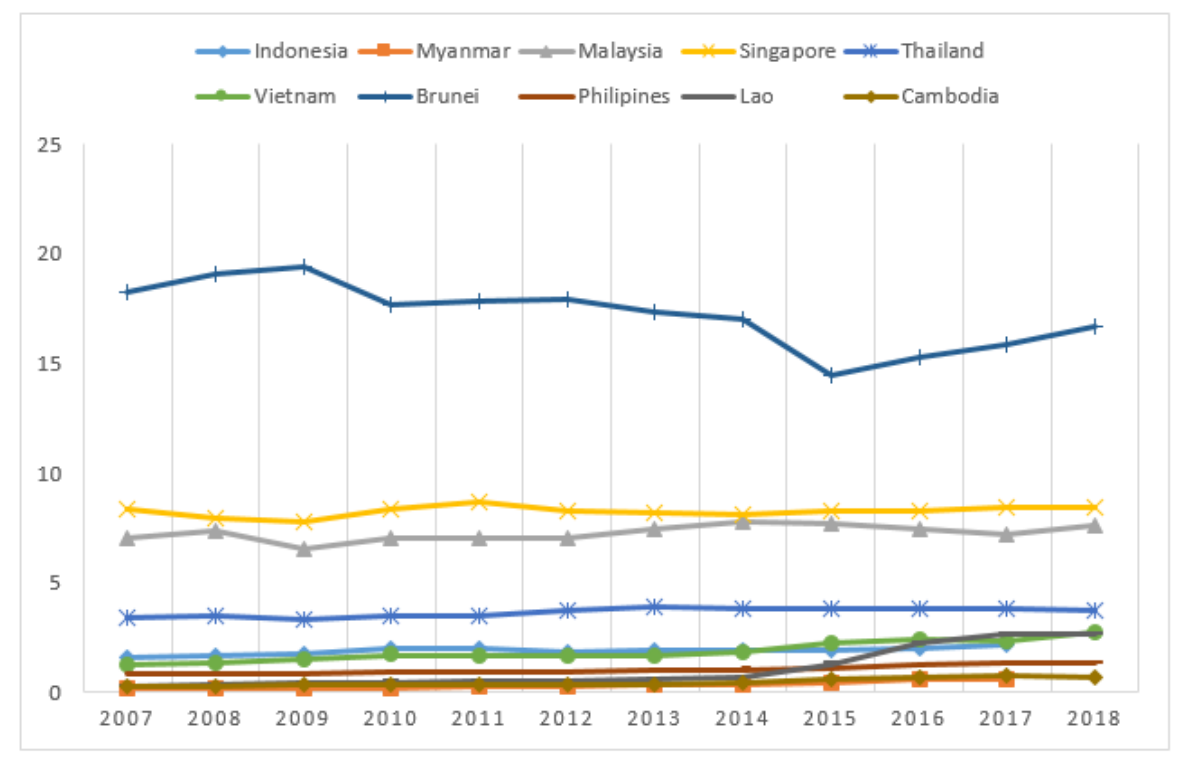

Fig. 2. Carbon Emissions for ASEAN Countries: Year 2007 - 2018

Figure 2 shows that Brunei is the country with the highest carbon emissions per capita di ASEAN from the year 2007-2018, followed by Singapore, Malaysia, Thailand, Indonesia and Vietnam. But since 2015, Vietnam and Lao Republic have risen above Indonesia.

\subsection{Logistics Performance and Carbon Emissions}

The important role of sustainable logistics performance is getting wider attention, especially because logistics activities involve the transportation sector which is considered the most responsible for greenhouse gas emissions in the world. Companies that adopt green logistics or sustainable logistics are also increasing. However, its effectiveness needs to be evaluated. Therefore, it is necessary to conduct a study to assess the relationship between the performance of logistics and emissions of carbon. 
Karaduman focusing his research in the relationship of logistics and carbon performance. The research was carried out in the Balkan countries using the LPI score [8]. Carbon performance and LPI were found to be significantly and positively correlated in Karaduman's research, means that country in Balkan that have higher scores of LPI tend to have fewer carbon emissions.

Liu using LPI data, analysing the impact of logistics performance on the degradation of environment. Tha data collected from 42 countries in Asia for the period of 2007 and 2016 [7]. The significant relationship is found between LPI and degradation of environment. Particularly, international shipping as a pillar of LPI, is found significantly reduces $\mathrm{CO} 2$ emissions, while the logistics timeliness pillar causes an increase in $\mathrm{CO} 2$ emissions. Based on the research results, other pillars of LPI such as tracing and tracking, service quality and competence, quality of infrastructure and efficiency of customs are closely related also to environment in various subregions in Asia.

In other study, combining CO2 emissions, LPI and consumption of oil from the transportation sector, Lu et al., developed an environmental logistics performance index (ELPI) to evaluate overall performance in green transport and logistics practices from 112 countries [17]. Their findings show a strong correlation between ELPI and LPI, income and region are closely related to the country's ELPI score also. The study concludes that, in general, countries with high LPI scores perform better in terms of green transportation. In this case, improving performance of green logistics and transportation can be done by implementing environmental regulations effectively and encouraging the use of clean energy.

The study conducted by Mariano et al., is aimed at evaluating the efficiency of the relationship between transportation logistics performance that measured using LPI, and emissions of $\mathrm{CO} 2$ from the transportation sector using the DEA approach and compiling a low-carbon logistics performance index (LPI) [18]. The results show that the best-performing countries measured by the low-carbon LPI are Germany, Japan, Benin, Togo, and the USA and the more developed countries include Luxembourg, Honduras, Ireland, and Lebanon.

Another study by Larson focused on the national logistics performance and sustainability dimensions relationship [19]. The results show that performance of logistics is a driver of successful economic and business activity, however it is also considered as a contributor to the of environment in the form of hazardous emissions. Growth of economic is indeed an important goal of every country, but its leaders are advised to emphasize also the importance of social welfare, technology and practices that use energy efficiently in transportation so as to reduce emissions to lower levels.

\subsection{Conceptual framework}

The development of this research instrument mainly refers to the study conducted by Liu et al.; Karaduman et al.; and Larson, which examines the effect of logistics performance on emissions of carbon in ASEAN for the period of 2007 - 2018 [7], [8], [19]. The following is the conceptual framework of this research: 


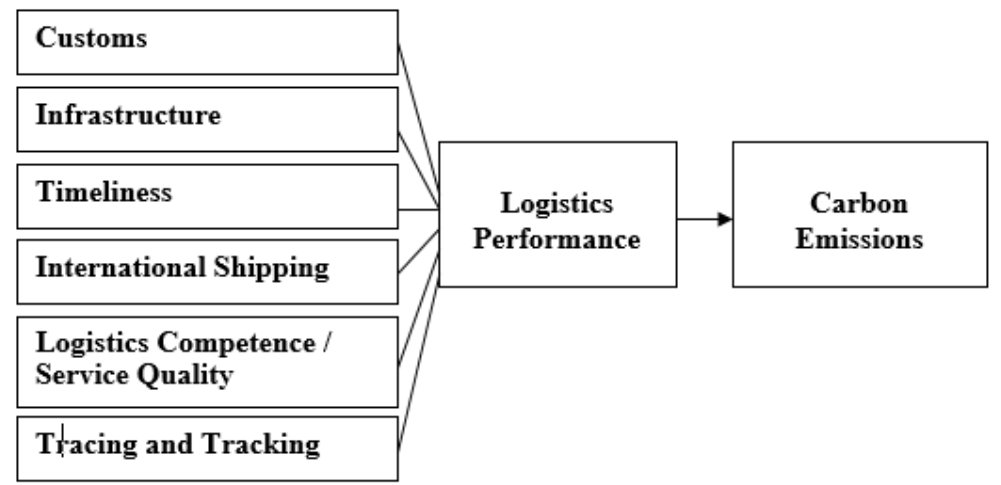

Fig. 3. Conceptual framework

\subsection{Hypothesis}

There are several studies conducted to examine the relationship of logistics performance and carbon emissions with various variables. Research by Liu et al.; Karaduman et al.; Mariano et al.; and Larson concluding a significant relationship between carbon emissions and logistics performance [7], [8], [18], [19]. Karaduman found a significant and positive relationship between the two variables in Balkan countries, means that higher LPI scores tend to have fewer emissions of carbon [8]. Research by Liu et al., show the significant relationship between performance of logistics and degradation of environment [7]. Particularly, international shipping as one of LPI pillars, significantly reduces $\mathrm{CO} 2$ emissions, while the logistics timeliness pillar causes an increase in $\mathrm{CO} 2$ emissions in 42 countries of Asia. The remaining pillars of LPI such as tracing and tracking, service quality and competence, quality of infrastructure and customs efficiency are also closely related to the environment in various subregions in Asia. While Larson focused the study on the relationship between national performance in logistics and sustainability dimensions [19]. It was found that logistics performance is an important driver of successful economic and business activity, but in other side it can contribute to degradation of environment in the form of hazardous emissions. Based on the results of these studies, the following hypotheses were developed:

a) Major hypothesis:

Ha. Logistics performance affects the carbon emission of ASEAN countries

b) Minor hypothesis:

H1. Customs affect the carbon emission of ASEAN countries

H2. Infrastructure affects the carbon emissions of ASEAN countries

H3. International shipping affects ASEAN countries' carbon emissions

H4. Logistics competence / service quality affects the carbon emissions of ASEAN countries

H5. Tracking and tracing affects the carbon emissions of ASEAN countries

H6. Timeliness affects the carbon emission of ASEAN countries 


\section{Research Methodology}

Data. This study focus on investigation of the relationship between logistic performance and carbon emission in all ASEAN member countries consisting of Singapore, Malaysia, Indonesia, Thailand, Cambodia, Laos, the Philippines, Myanmar, Brunei, and Vietnam. The data used is secondary data obtained from The World Bank Database, including logistics performance data (Logistics Performance Index $\{\mathrm{LPI}\}$ ) with it's six indicators, carbon emissions and data on control variables, namely trade and urban population for the period of 2007-2018.

Regression Model. To examine the relationship between LPI and carbon emission in ASEAN, panel data analysis method and Eviews software was used. The regression model was developed by adding control variables, namely trade and urban population as follows:

CEit $=\alpha+\beta 1$ LPIit $+\beta 2$ Urbnit $+\beta 3$ Tradeit $+\varepsilon$ it

Variable definition:

$\mathrm{CE} \quad=$ Carbon dioxide emission percapita

LPI = Logistic Performance Index

Urbn = Urban population ( $\%$ of total population $)$

Trade $=$ Trade $(\%$ of GDP $)$

$\varepsilon \quad=$ error term

\section{Results}

\subsection{Descriptive statistics}

Table 1 below shows a description of the value of Emissions (carbon emissions), LPI (logistics performance), Trade (trade value) and Urban (urban population) as a whole from ASEAN member countries. From table 1 it is known that carbon emissions from ASEAN countries range from 0.16 to 16.2 units per capita, while LPI ranges from 2.1 to 4.2. Singapore is the country with the highest LPI during the period 2007 - 2018, followed by Malaysia, Thailand, Vietnam and Indonesia. Malaysia always ranks second, but in 2018 it experienced a significant decline of LPI. Carbon emissions data shows that Brunei is the country with highest carbon emissions percapita in ASEAN from year 2007-2018, followed by Singapore, Malaysia, Thailand, Indonesia and Vietnam.

Table 1. Data Description of Emissions, LPI, Trade and Urban Period 2007 - 2018

\begin{tabular}{ccccc}
\hline & EMISSIONS & LPI & TRADE & URBAN \\
\hline Mean & 3.372098 & 3.025370 & 130.9334 & 49.61115 \\
Median & 1.764769 & 2.990000 & 120.7368 & 45.62600 \\
Maximum & 16.22622 & 4.190000 & 394.2885 & 100.0000 \\
Minimum & 0.158767 & 2.070000 & 22.38462 & 19.41300 \\
Std. Dev. & 3.712334 & 0.534242 & 91.35699 & 24.02835 \\
Skewness & 1.551979 & 0.471231 & 1.532178 & 0.885682 \\
Kurtosis & 5.156148 & 2.680471 & 4.754711 & 2.741140 \\
Jarque-Bera & 32.13795 & 2.228249 & 28.05589 & 7.210659 \\
Probability & 0.000000 & 0.328202 & 0.000001 & 0.027178 \\
Sum & 182.0933 & 163.3700 & 7070.404 & 2679.002 \\
\hline
\end{tabular}




\begin{tabular}{ccccc}
\hline & EMISSIONS & LPI & TRADE & URBAN \\
\hline Sum Sq. Dev. & 730.4154 & 15.12694 & 442343.3 & 30600.17 \\
Observations & 54 & 54 & 54 & 54 \\
Cross sections & 10 & 10 & 10 & 10 \\
\hline \multicolumn{5}{c}{ Source: Eviews ouput result }
\end{tabular}

\subsection{Results and Discussion}

\subsubsection{Relationship between LPI and Carbon Emissions}

The results of the analysis of the relationship between LPI and Carbon Emissions is presented in table 2 as follows:

Table 2. Results of the Relationship between LPI and Carbon Emissions

\begin{tabular}{|c|c|c|c|c|c|c|}
\hline \multirow[t]{2}{*}{ Variable } & \multicolumn{2}{|c|}{ COMMON } & \multicolumn{2}{|c|}{ FIXED } & \multicolumn{2}{|c|}{ RANDOM } \\
\hline & Beta & Prob & Beta & Prob & Beta & Prob \\
\hline $\mathrm{C}$ & 0.995681 & 0.6692 & -1.073940 & 0.3025 & -0.865724 & 0.4879 \\
\hline LPI? & -1.955285 & 0.0766 & -0.478352 & 0.0939 & -0.524890 & $0.0647 * *$ \\
\hline TDR? & 0.002694 & 0.5845 & 0.003770 & 0.0880 & 0.003790 & $0.0783 * *$ \\
\hline URB? & 0.159407 & 0.0000 & 0.108505 & 0.0000 & 0.118859 & $0.0000^{*}$ \\
\hline \multicolumn{7}{|c|}{ Goodness of Fit Model } \\
\hline Adj R-squared & \multicolumn{2}{|c|}{0.702125} & \multicolumn{2}{|c|}{0.995616} & \multicolumn{2}{|c|}{0.491382} \\
\hline F-statistic & \multirow{2}{*}{\multicolumn{2}{|c|}{$\begin{array}{l}43.42799 \\
0.000000\end{array}$}} & \multicolumn{2}{|c|}{1022.876} & \multicolumn{2}{|c|}{18.38999} \\
\hline Prob F-stat & & & \multicolumn{2}{|c|}{0.000000} & \multicolumn{2}{|c|}{0.000000} \\
\hline \multicolumn{7}{|c|}{ Model Test } \\
\hline Chow Test & \multicolumn{2}{|c|}{$\begin{array}{c}\text { Cross-section } \\
\text { Chi-square }\end{array}$} & \multicolumn{2}{|c|}{ Prob } & \multicolumn{2}{|c|}{ Keputusan } \\
\hline \multirow{3}{*}{ Hausman Test } & \multicolumn{2}{|c|}{242.703286} & \multicolumn{2}{|c|}{0.0000} & \multicolumn{2}{|c|}{ Ha diterima } \\
\hline & \multirow{2}{*}{\multicolumn{2}{|c|}{$\begin{array}{c}\text { Cross-section random } \\
5.514538\end{array}$}} & \multicolumn{2}{|c|}{ Prob } & \multicolumn{2}{|c|}{ Keputusan } \\
\hline & & & 0.13 & & $\mathrm{Ha}$ di & olak \\
\hline
\end{tabular}

Model Selection Test. Based on the results of the Chow Test in table 2, the prob value of the Chi-square cross-section is $0.0000<0.05$ (alpha 5\%), then the chosen model is FEM and the test is continued with the Hausman test. Based on the results of the Hausman Test, the probability value of Cross-section Random is $0.1378>0.05$ (alpha 5\%), it is concluded that the selected model is REM.

Data Panel Regression Results the Relationship of LPI and Carbon Emissions. Results of the significance test on the main hypothesis show that there is a negative relationship between LPI and carbon emissions which is significant at Alpha 10\%. Table 3 shows the prob value of $0.0647<0.10$, so it can be concluded that statistically there is a negative relationship between LPI and carbon emission.

These results are in line with the research of Karaduman et al. and Lu et al. [8], [17]. This may indicate that in general ASEAN countries have practiced good and environmentally friendly logistics management, which does not increase carbon emissions but instead reduces carbon emissions. Indeed, there are countries with high per capita carbon emissions, namely Brunei, Singapore and Malaysia, but the other seven countries have quite low carbon emissions. 
The results of the significance test on Trade as control variable show a prob value of $0.0783<0.10$ (Alpha 10\%) so it can be concluded that statistically there is positive effect of Trade on Carbon Emissions. Furthermore, results of the significance test on Urban Population as control variable can also be statistically concluded that there is a positive influence on Carbon Emissions, supported by a prob value of $0.0000<0.05$ (Alpha 5\%). There are indications that trade and urban population can increase fuel-consuming economic activities such as transportation, for example, which has the potential to increase carbon emissions.

\subsubsection{Relationship between LPI Indicators and Carbon Emissions}

The following table presents the results of analysis of the relationship between LPI Indicators and Carbon Emissions:

Table 3. Results of the Relationship between LPI Indicators and Carbon Emissions

\begin{tabular}{|c|c|c|c|c|c|c|}
\hline \multirow[t]{2}{*}{ Variabel } & \multicolumn{2}{|c|}{ COMMON } & \multicolumn{2}{|c|}{ FIXED } & \multicolumn{2}{|c|}{ RANDOM } \\
\hline & Beta & Prob & Beta & Prob & Beta & Prob \\
\hline $\mathrm{C}$ & 1279.104 & 0.0614 & -2778.378 & 0.0006 & -1908.020 & 0.0008 \\
\hline CUST & -3.488134 & 0.9836 & -19.02926 & 0.2855 & -12.35260 & 0.1628 \\
\hline INFR & 49.57654 & 0.7004 & -25.64433 & 0.0690 & -20.47209 & $0.0049 *$ \\
\hline IS & -64.64388 & 0.8404 & 42.66377 & 0.2138 & 31.13733 & $0.0156^{*}$ \\
\hline LQC & 18.20936 & 0.8121 & 2.083402 & 0.7990 & 0.548134 & 0.9090 \\
\hline $\mathrm{TT}$ & -1.808336 & 0.9059 & 0.151162 & 0.9247 & 0.319570 & 0.7962 \\
\hline TIME & -7.340345 & 0.9502 & 3.438943 & 0.7866 & 3.255579 & 0.3229 \\
\hline TRD & 2.154856 & 0.5624 & 0.035187 & 0.9830 & -0.633360 & 0.6067 \\
\hline URB & -14.97504 & 0.3076 & 69.61936 & 0.0000 & 51.14980 & $0.0000^{*}$ \\
\hline \multicolumn{7}{|c|}{ Goodness of Fit Model } \\
\hline Adj R-squared & \multicolumn{2}{|c|}{-0.121906} & \multicolumn{2}{|c|}{0.990597} & \multicolumn{2}{|c|}{0.174756} \\
\hline F-statistic & \multicolumn{2}{|c|}{0.266544} & \multicolumn{2}{|c|}{335.6558} & \multicolumn{2}{|c|}{2.429395} \\
\hline Prob F-stat & \multicolumn{2}{|c|}{0.973607} & \multicolumn{2}{|c|}{0.000000} & \multicolumn{2}{|c|}{0.027903} \\
\hline \multicolumn{7}{|c|}{ Uji Pemilihan Model } \\
\hline Chow Test & \multicolumn{2}{|c|}{$\begin{array}{l}\text { Cross-section } \\
\text { Chi-square }\end{array}$} & \multicolumn{2}{|c|}{ Prob } & \multicolumn{2}{|c|}{ Keputusan } \\
\hline \multirow{3}{*}{ Hausman Test } & \multicolumn{2}{|c|}{274.974250} & \multicolumn{2}{|c|}{0.0000} & \multicolumn{2}{|c|}{ Ha diterima } \\
\hline & \multirow{2}{*}{\multicolumn{2}{|c|}{$\begin{array}{c}\text { Cross-section random } \\
14.187268\end{array}$}} & \multicolumn{2}{|c|}{ Prob } & \multicolumn{2}{|c|}{ Keputusan } \\
\hline & & & 0.07 & & $\mathrm{Ha}$ di & lak \\
\hline \multicolumn{7}{|l|}{ * Alpha 5\% } \\
\hline Source: Eview & dlt & & & & & \\
\hline
\end{tabular}

Model Selection Test. Based on table 4, the results of the Chow Test show that the chosen model is FEM and based on the results of the Hausman Test, the REM model is selected.

Data Panel Regression Results of the Relationship of LPI Indicators and Carbon Emissions. Based on table 3 about the individual testing of each logistics performance indicator, the results shown that there is a negative influence of infrastructure on carbon emissions, proven by the prob value of $0.0049<0.05$ (Alpha 5\%). This means that the better the performance of the infrastructure, the carbon emissions will decrease. Furthermore, it is found a positive effect of international shipping on carbon emission with a prob value of $0.0156<0.05$ (Alpha 5\%). This result indicates that international shipping activities could increase carbon emissions. While the analysis results for indicator customs, logistics 
competence and quality, tracking and tracing, and timeliness are not significantly related to carbon emissions.

These results indicate that the infrastructure in ASEAN has been quite environmentally friendly, proven to be able to reduce carbon emissions. However, the international shipping indicator, on the contrary, is positively related to carbon emissions. The other 4 indicators are not significant enough to relate to carbon emissions. This result is not in line with [7] research in Asia and [19], where LPI indicators are generally correlated with environmental degradation.

\section{Conclusion}

To achieve the realization of sustainable development goals, business practices can no longer only focus on economic aspects, but also social and environmental aspects. One of the big challenges facing the whole world today is the problem of global warming caused by carbon emissions. Supply chain and logistics activities get a lot of attention related to this issue of carbon emissions.

Goal of this study is to determine the relationship between carbon emissions and logistics performance. From the analysis of panel data on 10 ASEAN member countries, the study results show a negative and signififant relationship of logistics performance on carbon emission. This means that the higher the logistics performance of ASEAN countries, the lower carbon emissions will be. In other words, environmental performance will get better. This shows the effectiveness of logistics management in ASEAN countries in general is getting better and does not result in an increase in carbon emissions. So that the environmental aspects of logistics activities in ASEAN have been sustainable. These finding is in line with the research of [8], [17].

Individual testing of the LPI indicator shows that there are only two indicators that are significantly related to carbon emissions, namely infrastructure and international shipping, but in opposite directions, while the remaining indicators are not related to carbon emissions. Infrastructure in ASEAN has shown to be environmentally friendly, because it is able to reduce carbon emissions. ASEAN needs to focus on international shipping which has been shown to be positively related to carbon emissions.

\section{References}

[1] J.-F. Arvis et al., "Connecting to Compete 2018," Washington DC, 2018. doi: $10.1596 / 29971$.

[2] J.-F. Arvis et al., "Connecting to Compete 2018: Trade Logistics in the Global Economy," Washington DC, 2018. [Online]. Available: http://hdl.handle.net/10986/29971.

[3] B. Erkan, "The Importance and Determinants of Logistics Performance of Selected Countries," Financ. Bank., vol. 3, no. 6, pp. 1237-1254, 2014.

[4] A. A. P. Bîzoi and C. A. Sipos, "Logistics Performance and Economic Development A Comparison within the European Union," in Multidisciplinary Academic COnference on Economics, Management, and Marketing, 2014, pp. 1-8, doi: 10.13140/2.1.1789.2163.

[5] J.-F. Arvis, M. A. Mustra, L. Ojala, B. Shepherd, and D. Saslavsky, "LPI 2012 - 
Connecting to Compete, Trade Logistics in the Global Economy," Washington DC, 2012.

[6] B. Hofman, "Performance and Prospects of Global Logistics: Keynote speech at the CaiNiao Global Smart Logistics Conference," The World Bank, 2017. https://www.worldbank.org/en/news/speech/2017/05/22/performance-and-prospectsof-global-logistics.

[7] J. Liu, Y. Feng, Q. Zhu, and J. Sarkis, "Green supply chain management and the circular economy: Reviewing theory for advancement of both fields," Int. J. Phys. Distrib. Logist. Manag., vol. 48, no. 8, pp. 794-817, 2018, doi: 10.1108/IJPDLM-012017-0049.

[8] H. A. Karaduman, A. Karaman-Akgül, M. Çağlar, and H. E. Akbaş, "The relationship between logistics performance and carbon emissions: an empirical investigation on Balkan countries," Int. J. Clim. Chang. Strateg. Manag., vol. 12, no. 4, pp. 449-461, 2020, doi: 10.1108/IJCCSM-05-2020-0041.

[9] L. Ojala and D. Celebi, “The World Bank's Logistics Performance Index ( LPI ) and drivers of logistics performance," 2015.

[10] K. Rashidi, "Sustainable supplier selection in the logistics industry: A comparison of alternative approaches," University of Gothenburg, 2019.

[11] R. H. Ballou, "Business logistics: importance and some research opportunities," Gestão \& Produção, vol. 4, no. 2, pp. 117-129, 1997, doi: 10.1590/s0104530x1997000200001.

[12] P. Rushton, A., Croucher, P. and Baker, Handbook of logistics and distribution management. London: Kogan Page Limited, 2014.

[13] C. Sunil and M. Peter, Supply Chain Management: Strategy, Planning, And Operation. India: Pearson, 2013.

[14] D. Simchi-Levi, "The Master of Design. An Interview with David Simchi-Levi," Supply Chain Manag. Rev., vol. 4, 2000.

[15] H. H. Chang, Y.-C. Tsai, and H. Che-Hao, "E-procurement and supply chain performance," Supply Chain Manag., vol. 18, no. 1, pp. 34-51, 2013, doi: $10.1108 / 13598541311293168$.

[16] J.-F. Arvis, M. Alina Mustra, J. Panzer, L. Ojala, and T. Naula, "Connecting to Compete 2007: Trade Logistics in the Global Economy--The Logistics Performance Index and Its Indicators," Washington DC, 2007. doi: 10.1596/24600.

[17] M. Lu, R. Xie, P. Chen, Y. Zou, and J. Tang, "Green transportation and logistics performance: An improved composite index," Sustain., vol. 11, no. 10, pp. 1-17, 2019, doi: $10.3390 /$ su11102976.

[18] E. B. Mariano, J. A. Gobbo, F. de C. Camioto, and D. A. do N. Rebelatto, "CO2 emissions and logistics performance: a composite index proposal," J. Clean. Prod., vol. 163, pp. 166-178, 2017, doi: 10.1016/j.jclepro.2016.05.084.

[19] P. D. Larson, "Relationships between logistics performance and aspects of sustainability: A cross-country analysis," Sustain., vol. 13, no. 2, pp. 1-13, 2021, doi: 10.3390/su13020623. 